\title{
Quantifying the Value of Open Source Hardware Development
}

\author{
Joshua M. Pearce1,2 \\ ${ }^{1}$ Department of Materials Science \& Engineering, Michigan Technological University, Houghton, MI, USA \\ ${ }^{2}$ Department of Electrical \& Computer Engineering, Michigan Technological University, Houghton, MI, USA \\ Email: pearce@mtu.edu
}

Received 25 November 2014; revised 15 December 2014; accepted 25 December 2014

Copyright (C) 2015 by author and Scientific Research Publishing Inc.

This work is licensed under the Creative Commons Attribution International License (CC BY). http://creativecommons.org/licenses/by/4.0/

(c) (i) Open Access

\section{Abstract}

With the maturation of digital manufacturing technologies like 3-D printing, a new paradigm is emerging of distributed manufacturing in both scientific equipment and consumer goods. Hardware released under free licenses is known as free and open source hardware (FOSH). The availability of these FOSH designs has a large value to those with access to digital manufacturing methods and particularly for scientists with needs for highly-customized low-volume production products. It is challenging to use traditional funding models to support the necessary investment of resources in FOSH development because of the difficulty in quantifying the value of the result. In order to overcome that challenge and harvest the current opportunity in both low-cost scientific equipment and consumer products, this article evaluates the following methods to quantify the value of FOSH design including: 1) downloaded substitution valuation; 2) avoided reproduction valuation and 3) market savings valuation along with additional benefits related to market expansion, scientific innovation acceleration, educational enhancement and medical care improvement. The strengths and weaknesses of these methods are analyzed and the results show that the methods are relatively straight-forward to institute, based on reliable freely-available data, and that they minimize assumptions. A case study of a syringe pump with numerous scientific and medical applications is presented. The results found millions of dollars of economic value from a relatively simple scientific device being released under open-licenses representing orders of magnitude increase in value from conventional proprietary development. The inescapable conclusion of this study is that FOSH development should be funded by organizations interested in maximizing return on public investments particularly in technologies associated with science, medicine and education.

\section{Keywords}

Open Hardware, Free and Open Source Software, Positive Externalities, Value, Valuation 


\section{Introduction}

With the maturation of digital manufacturing technologies like 3-D printing, a new paradigm of production is emerging of distributed manufacturing [1]-[4] where users, whether scientists [5] [6] or simply consumers [7] [8], fabricate products themselves from digital plans. As scientists have pushed 3-D printing technology to the limits of advanced materials, nanoscale and bioprinting [9]-[12] following conventional technological and economic development, there has been an exponential rise in designs for hardware released under open-source, creative commons licenses or placed in the public domain [13] including the 3-D printers themselves [14] [15]. Such free and open source hardware (FOSH or open hardware) is shared by providing the bill of materials, schematics, assembly instructions, and procedures needed to fabricate a digital replica of the original. Open hardware is thus hardware benefiting from the mass-scale peer review and collaboration, which has been shown to be a successful method of developing free and open source software [16]-[18]. The availability of these designs has a large value to those with access to digital manufacturing methods [13] and has driven the explosive growth in 3-D printing [19]. For scientists that need access to highly-customized low-volume products, this alternative method of manufacturing can have extremely high value [5] [20] [21]. Although some of the designs for both scientific equipment and more common household goods were developed by professionals or highly-skilled amateurs, the majority of the designs are relatively unsophisticated leaving considerable opportunity for improvement with an investment in the design of FOSH. It is challenging to use traditional funding models to support the necessary investment of resources in FOSH because of the difficulty in quantifying the value of making such an investment. In order to overcome that challenge and harvest the current opportunity in both low-cost scientific equipment and consumer products this paper: 1) reviews the methods to quantify the economic value of developing free and open source hardware designs; 2) compares the strengths and weaknesses of the methods and 3) provides recommendations to policy makers for maximizing the return on investment in research and development in any field accessible to open hardware design.

\section{Methods}

Three methods and their variations are explored to quantify the value of FOSH design: 1) downloaded substitution valuation; 2) avoided reproduction valuation and 3) market savings valuation.

\subsection{Downloaded Substitution Valuation}

The downloaded substitution valuation uses the number of times that a FOSH design is accessed on the Internet to quantify the value of the design. The downloaded valuation for substitution savings, $V_{\mathrm{D}}$, is:

$$
V_{D}(t)=\left(C_{p}-C_{f}\right) \times P \times N_{D}(t)
$$

where $C_{p}$ is the cost to purchase a traditionally manufactured product, $C_{f}$ is the marginal cost to fabricate it digitally using a distributed technique, $P$ is the percent of downloads resulting in a product, and $N_{D}(t)$ is the number of times the digital design has been downloaded at time $t . P$ is subject to error as downloading a design does not indicate that it was manufactured and on the other hand, a single download from a distribution website could be fabricated many times, traded via email, memory stick or posted on P2P sites that are not recorded. The savings from FOSH digital manufacturing $\left(S=C_{p}-C_{f}\right)$ have been shown to be substantial in the developing world for appropriate technology [8] and for consumer goods (e.g. cellphone cases) [13]. $S$ is maximized for custom low-volume products such as scientific equipment where $C_{f}$ is generally only $1 \%-10 \%$ of $C_{p}$ [20] [21]. However, $S$ can change with time and the number of total downloads would increase with time. These future values are unknown, but can be extrapolated by a number of methods to give the total downloaded valuation $\left(V_{\mathrm{DT}}\right)$ discounted to the present:

$$
V_{\mathrm{DT}}=\sum_{t=1}^{T}\left(C_{p}(t)-C_{f}(t)\right) \times P \times\left(\frac{\left[N_{D}(t)\right]}{(1+i)^{t}}\right)
$$

where $i$ is the discount rate. Predicting the use of technologies in the future is challenging and there are many innovation diffusion models that can be used for specific products [22]-[25]. 


\subsection{Avoided Reproduction Valuation}

A variation of the downloaded valuation is the avoided cost of reproduction value $V_{R}$ for a single company, which is given by:

$$
V_{R}=h \times w
$$

where $h$ is the number of design hours needed to replicate the product and $w$ is the hourly wage of the workers needed to produce the replication. This method of capturing value can also be extrapolated to all firms (and individuals that would hire firms or freelance designers to complete the design) to obtain the total value to society and is given by:

$$
\tilde{V}_{r t}(t)=\sum_{t=1}^{T}\left(\frac{\left(h \times w \times P \times N_{D}(t)\right)}{(1+i)^{t}}\right)
$$

where $i$ is the discount rate and it is assumed that there is no variation in wages or design time efficiency. Taking both of these variables into account provides:

$$
V_{r t}(t)=\sum_{n=1}^{J} h_{n} \times w_{n}
$$

where the variable time to complete the design and wages needed to do it are taken into account for $J$ types of jobs. To account for the value for all of time $(t)$ :

$$
V_{\mathrm{RT}}=\sum_{t=1}^{T}\left[\frac{V_{r t}(t)}{(1+i)^{t}}\right]=\sum_{t=1}^{T}\left[\frac{\sum_{n=1}^{J} h_{n} \times w_{n}}{(1+i)^{t}}\right]
$$

\subsection{Market Savings Valuation}

The third approach assumes that sometime in the future the exponential rise in digital replication technologies such as 3-D printers [19] is saturated and that the distributed manufactured item is either so superior because of cost savings or customization options that it can approximately capture the entire market for a given product. The value of the entire market is thus:

$$
V_{M}(t)=M(t)-\left(C_{f}(t) \times N_{M}(t)\right)
$$

The sum of the market over $T$ years can be calculated and converted to a net present total market value $\left(V_{\mathrm{MT}}\right)$ by:

$$
V_{\mathrm{MT}}=\sum_{t=1}^{T} \frac{\left[M(t)-\left(C_{f}(t) \times N_{M}(t)\right)\right]}{(1+i)^{t}}
$$

where $M(t)$ is the current market in year $t$ in US dollars and $N_{M}(t)$ is the total number of products of a specific type that make up market $M$.

\subsection{Secondary Streams of Value}

All three core methods can be extended, as there are additional second order effects in providing value to the commons. Additional value can be tallied for educational benefits $\left(V_{\mathrm{ED}}\right)$, health benefits that increase longevity and productivity $\left(V_{\mathrm{MED}}\right)$, those that enhance science and engineering development $\left(V_{\mathrm{SCI}}\right)$, and a catch all of others $\left(V_{\text {отн }}\right)$. Thus, Equation 1(b) from the downloaded substitution valuation is expanded to provide the total value for all time:

$$
V_{\mathrm{DT}}^{\prime}=V_{\mathrm{DT}}+\sum_{t=1}^{T} \frac{\left[V_{\mathrm{ED}}(t)+V_{\mathrm{MED}}(t)+V_{\mathrm{SCI}}(t)+V_{\mathrm{OTH}}(t)\right]}{(1+i)^{t}}
$$


Similarly, Equation 2(d) from the avoided reproduction valuation method 2 becomes:

$$
V_{\mathrm{RT}}^{\prime}=V_{\mathrm{RT}}+\sum_{t=1}^{T} \frac{\left[V_{\mathrm{ED}}(t)+V_{\mathrm{MED}}(t)+V_{\mathrm{SCI}}(t)+V_{\mathrm{OTH}}(t)\right]}{(1+i)^{t}}
$$

Finally, in the market savings valuation, the total market for a given product would likely expand because of the lower costs, superior customization or a combination of both. As the cost of the product has decreased by $S$, an extra value, $V_{\mathrm{EC}}$, is derived from expanding the market. Thus, the total value of market savings and these additional benefits (market total plus or $V_{\mathrm{MT}}^{\prime}$ is now given by:

$$
V_{\mathrm{MT}}^{\prime}=V_{\mathrm{MT}}+\sum_{t=1}^{T} \frac{\left[V_{\mathrm{EC}}(t)+V_{\mathrm{ED}}(t)+V_{\mathrm{MED}}(t)+V_{\mathrm{SCI}}(t)+V_{\mathrm{OTH}}(t)\right]}{(1+i)^{t}}
$$

\section{Case Study}

The abstract equations above are conceptually simple, yet can be challenging to adapt to real-world conditions. To demonstrate how to extract the calculated values with the lowest possible error a case study to determine the value of an open-source syringe pump (OSSP) design [26] is analyzed to represent scientific tool, which may be government funded for scientific innovation acceleration, but also have applications in STEM education and medicine.

An OSSP library [26] was designed using open-source and freely available OpenSCAD, which is script-based and parametric CAD software possessing powerful 3-D modeling capabilities [27]. The majority of the pump parts can be fabricated with an open-source RepRap 3-D printer and readily available parts such as a stepper motor and steel rods [28]. The design, bill of materials and assembly instructions are globally available to anyone wishing to use them [29]. The OSSP can be used as a wireless control device attached to an open-source Raspberry Pi computer [30]. Performance of the OSSP was found to be consistent with the quality of commercial syringe pumps [26]. The low-cost OSSPs are completely customizable allowing both the volume and the motor to scale for specific applications such as any research activity including carefully controlled dosing of reagents, pharmaceuticals, and delivery of viscous 3-D printer media among other applications.

\subsection{Method $1 V_{\mathrm{DT}}$}

The designs for the OSSP were released in Sept. 2014 and in one month the designs had been downloaded from two digital repositories a total of $N_{D}=424$ times (114 on Thingiverse [31] and 310 on Youmagine [32]). The cost to purchase a traditionally manufactured syringe pump, $C_{p}$, ranges from $\$ 260$ - $\$ 1509$ for a single pump and $\$ 1800$ - \$2606 for a dual pump [26]. $C_{f}$ for the materials for a single OSSP is $\$ 97$ and for the double OSSP is \$154 [26]. The time to assemble either the single or double OSSP is less than an hour and can be accomplished by a non-expert. Although the time to print the components is less than four hours on a conventional RepRap, workers can do other tasks while printing. The assembler hourly rate is assumed to be $\$ 10 /$ hour because no special skills are needed. $P$ was assumed to be 1 as informal discussions with 50 RepRap owners found that the vast majority of designs downloaded were printed. This assumption has some error associated with it as $P$ could be less than one if downloaders decided not to make one; however, $P$ could be greater than one if downloaders made multiple copies or much greater than one if a single downloader decided to commercialize the syringe pump. This provides a savings, $S$, for substituting the OSSP for a commercial one of $\$ 153$ to $\$ 1402$ for a single and $\$ 1636$ to $\$ 2442$ for the double pump. Thus, following equation 1a the value $V_{\mathrm{DT}}$ of the OSSP library after one month ranged from over $\$ 64,000$ to over $\$ 1,000,000$ for $P=1$. Performing even a simple linear extrapolation in Equation 1(b) for a single year provides a $V_{\mathrm{MT}}$ between $\$ 778,000$ and $\$ 12.4$ million. Obviously, this calculation can be expanded out for more years, but then as equation $1 \mathrm{~b}$ shows the discount rate must be taken into account, which can vary depending on the organization or individual performing the analysis.

These results provide a factor of 12 spread in potential value based off the purchase price of syringe pumps. It should be pointed out that the low end value is from a simple infusion pump with considerably less functionality than the FOSH syringe pumps. Although it is possible that some of the downloaders only needed a simple infusion pump, the majority would be likely to be replacing more sophisticated devices. In addition, the FOSH li- 
brary allows for more programmable control than any of the other pumps on the market, thus it appears reasonable to estimate the value using a mid-range pump such as the GenieTouch Syringe Pump for $\$ 675(S=\$ 568)$. This provides a $V_{\mathrm{MT}}$ following method 1 of over $\$ 240,800$ for the first month and about \$2.9 million extrapolated for year one in value to the global scientific commons.

Some points should be made here concerning the potential errors in the $V_{\mathrm{DT}}$ estimates. Although the instructions for the OSSP had been accessed 5745 times, only 424 people (or about 7\%) chose to download it. It is possible that similarly the behavior of downloaders could distort $P$ up or down and detailed survey studies would be needed to better assess its value. In addition, using the OSSP library it is possible to make even more sophisticated and valuable equipment. For example, for $\$ 308$ in parts one can construct a quad-syringe pump using the FOSH design library, but to purchase a Cole-Parmer Continuous Flow Syringe Pump with four syringes costs $\$ 3947$, which is an $S$ of over $\$ 3600$ for a single download.

\subsection{Method $2 V_{\mathrm{RT}}$}

The mechanical designs for the OSSP were completed by experienced engineers in $<6$ worker-hours. To print and revise the five 3-D printed components took 3 hours, assembly less than 1 hour and software development and $\mathrm{Pi}$ wiring less than 16 hours. The total design and prototyping time was less than 26 hours (h). This schedule was possible because the designers were experienced with similar designs and had access to all of the components. According to Glassdoor, the median annual salary for a CAD engineer is $\$ 89,000$ [33] and for a software engineer it is $\$ 90,374$ [34] so using $\$ 89,000$ /year and ignoring overhead and benefits costs to be conservative for a 50 week year working 40 hours per week the $w$ is $\$ 44.50 . V_{R}$ from Equation 2(a) is thus $\$ 1157$. With the cost of the parts for a single OSSP being $\$ 97$, the total cost for the first pump for a firm designing it is $\$ 1254$, which is more expensive than the lowest-cost syringe pumps, but still would provide savings for the high-range products. Thus, it would be rational for syringe pumps to have been designed in-house before and there is some evidence of this as there are some published syringe pump singular designs [35]-[37]. These other designs were not pump libraries, although they would provide solutions for a sub-set of syringe pump users. It should be noted that less-experienced designers would take considerably longer to make a syringe pump and as syringe pump design outside the core competency of most firms it is unlikely that in-house syringe pump design is very widespread. A detailed survey would be needed to ascertain this with certainty, but is unnecessary for the purposes of calculating values of FOSH designs.

Now using the $N_{D}=424$ as a proxy for firms that may be willing to either complete the design themselves or hire a freelancer, Equation 2(b) after the first month is over $\$ 490,000$ and using the same extrapolation to the first year would be over $\$ 5.8$ million. If the slightly more sophisticated granular resolution on the wages is used the values of Equation 2(d) becomes $\$ 1167.99$ (\$11 difference from $2 b$ ).

\subsection{Method $3 V_{M}$}

Method 3 is the most straight-forward calculation if solid data on total market size, which are often tabulated by marketing firms and industry trade groups, can be obtained. Despite the OSSP being superior technically and a lower cost than commercial pumps it would not capture the entire market in the first year. Determining when this would occur based on a month of downloading statistics would obviously cause significant error. In general, method 3 should only be used for products that have been available long enough to gain a significant market share. For the purposes of demonstration in this case study it is assumed that the market penetration reaches maturity in five years as syringe and infusion pump manufacturers adopt the design and eliminate their existing products or simply leave the market because of price pressure from FOSH firms. Transparency Market Research [38] determined the global infusion pumps market was valued at $\$ 5.4115$ billion in 2012 and of that roughly $\$ 1$ billion was from syringe pumps and is expected to grow at a compound annual growth rate of $5.3 \%$ to reach an estimated value of S1.3 billion by 2019 [38]. To be conservative, it is assumed that it there is a step function in value at year five and it is assumed that this market is made up of only low-cost (\$260) pumps so the 2019 market is $\sim 5$ million pumps. Thus, if the FOSH syringe pump captured the entire 2019 market it would result in about $\$ 767$ million in value saved for the global community that year and every year after. It is unlikely that all of the research syringe pumps were included in this total approximate market determined by TMR, but the value is so much greater than the conservative estimates of the linear extrapolations of downloads that this under-approximation will be ignored. The greatest source of error with this method is determining the market pe- 
netration rates and time until total market capture. To occur this demands a robust and growing open-source hardware business community.

\subsection{Secondary Streams of Value}

By necessity the calculations of the secondary streams of value are the most speculative with the largest margin for error without the use of focused studies. For the OSSP, four additional revenue streams will be discussed: increased market, research and educational benefits, and medical benefits.

\subsubsection{Increased Market}

As the OSSP represents a savings of between 59\% - 93\%, if it gains significant market penetration it can be expected to increase the market for syringe pumps. To determine the scale of this market response the price elasticity of demand is needed, which is the quantity demanded of a good to a change in its price (e.g. the percentage change in quantity demanded in response to a one percent change in price). The elasticity of demand for goods in general and syringe pumps in particular can be affected by several factors [39]. First, there are no real substitutes for a syringe pump indicating that demand would be inelastic [40]. Syringe pumps in general are not purchased by consumers - rather hospitals and laboratories. While they are expensive they represent a small percentage of such institutional income or budgets. Thus, the income effect will be insignificant and demand inelastic [41]. The relatively long lifetimes of syringe pumps would again make them less elastic. Brand loyalty would be expected to offer the largest barrier to OSSP adoption, particularly for medical applications although even researchers may be less likely to adopt a pump if they are not completely sure its reliability is vetted. This would result in inelastic demand [41]. Thus, it is not prudent to assume that the syringe pump market is perfectly elastic. Here, if a relativity inelastic ratio of $1 \%$ demand increase for each $10 \%$ drop in price the syringe pump market is assumed, the market might be expected to increase between about $5.9 \%-9.3 \%$, which in 2019 would be between an additional value of $\$ 45$ - $\$ 71$ million. This value is cut in half as an approximation of value, as the first extra OSSP sold saves very close to values calculated. However, for the last extra unit sold the benefit is equal to the new cost, so there is no net savings.

\subsubsection{Research and Educational Benefits}

The OSSP was originally designed for university research labs and published in the peer-reviewed literature. As the pump meets the standards for research and has already been vetted it seems reasonable that it would be mostly likely to be adopted university labs first. Thus, there are potential additional value that the FOSH design provides for both scientific research and education.

The value of the FOSH in labs is not only the dollar amount saved for research, but also includes the value of the overhead (indirect costs) charged on grants to purchase the equipment. The national average of overhead costs among universities is 52\% [42]. These overhead rates are primarily used to subsidize administrative salaries and building depreciation [42] and have lead to a practice of rating universities by research expenditures, which perversely provide an incentive to increases these rates while depressing the use of FOSH [43]. This would lead to FOSH values of over \$4.3 million and over \$2.7 million for methods 1 and 2, respectively.

By decreasing the costs of research equipment more resources are available to do science. For example, if a quad syringe pump is fabricated for a molecular biology lab the savings would be enough to hire a summer student presumably increasing the scientific discovery rate. In addition, if syringe pumps used for electrospinning novel materials represented a bottleneck to scientific discovery for a chemistry lab, being able to make between 2 to 14 OSSPs for the price of commercial alternatives would relieve that bottleneck and increase the rate of scientific discovery. Quantifying the value of an increased rate of discovery entails a specific study in each lab that would need to be done after the discoveries were made with controls for similar labs operating with less or inferior equipment. Qualitatively, however, it is clear that FOSH that has scientific applications and that costs less than commercial offerings has values set by the minimums of the three core methods.

Similarly, if because of its lower costs the OSSP was able to be used in the classroom or lab courses at either the university or pre-college education, the improved education that students received because of access to it would be positive as would the tertiary effects of their contribution to the economy. Again, future work is needed in specific case studies to ascertain this value, however, for the purposes of this study it is clear that any FOSH that have educational applications and that costs less than commercial offerings has values set by the minimums of the three core methods. 


\subsubsection{Medical Benefits}

The primary market for syringe pumps is in the applied medical field. The OSSP could technically be used for medical applications now, however, outside of areas where technical viability dominates use patterns (e.g. developing world) the pump would need to go through extensive testing and certification because of liability concerns. For this to occur either an NPO, government agency or one or several businesses will need to make the investment in the certification and testing. When the vetting and certification is complete and the OSSP is being used at several hospitals a study could be run investigating the effect of the decreased costs for the use of syringe pumps has on the hospitals overall cost of care. This could be calculated in terms of quality adjusted life years (QALY) [44] and then multiplied by the pro-rated value of a human life [45]-[47]. Regardless of which model is used to calculate the value of a human life it is clear that even a fractional life saved would result in additional value created by FOSH development that had medical applications. It should also be pointed out that these values would tend to accrue in regions where low-cost medical equipment is sorely needed now [48] [49].

\subsubsection{Other Value}

Finally, there are other potential values from FOSH development. It has been shown that in most cases distributed manufacturing using 3-D printing has positive environmental benefits over traditional centralized manufacturing and shipping [50]. It can be assumed that the distributed manufacturing of the OSSP would have some additional value because of reduced environmental impact. For distributed manufacturing of 3-D components the potential to use recyclebots to produce filament from waste plastic [51] or to use solar-powered 3-D printers [52] reduces the environmental impact further. In this particular case this impact is small because of the size of a syringe pump but could be significant if scaled to the entire market and can all be quantified, by adding up the benefits of pollution prevention [53].

\section{Discussion}

The values determined by the methods are summarized in Table 1 .

The case study supports the results that should be self-evident that the following three relationships are true for the three primary methods of evaluating the economic benefit of OSH:

$$
\begin{gathered}
V_{D}<V_{\mathrm{DT}}<V_{\mathrm{DT}}^{\prime} \\
V_{R}<V_{r t}<V_{\mathrm{RT}}<V_{\mathrm{RT}}^{\prime} \\
V_{M}<V_{\mathrm{MT}}<V_{\mathrm{MT}}^{\prime}
\end{gathered}
$$

The three methods provided in this paper all benefit from the fact that the inputs are generally available, have low associated errors and the calculations are straight forward. Method 1 is simply scaling economic savings from distributed manufacturing that has been previously demonstrated [13]. Method 2 using development costs is similar to that employed to calculate the value of Linux [54]. Method 3 is only valid when the FOSH has dominated the entire market and should thus be viewed as an upper bound, with the market elasticity caveat. Table 2 summarizes the advantages and disadvantages of each method. These methods are superior to the more amorphous methods used to calculate the value of larger projects such as maps by Google [55], GPS [56], or the value of the Internet [57]. The methods presented in this paper all have the advantage that if minor errors are allowed in $P$ detailed studies can be avoided. It should be noted with modest improvements in FOSS for 3-D printing to count actual prints in an anonymous and secure way, a technique such as those used to estimate the

\begin{tabular}{|c|c|c|c|c|}
\hline Method (estimate) & Value & With Market Increase & With Educational Overhead & $\begin{array}{l}\text { With Research, Education, } \\
\text { Medical and/or Other Benefits }\end{array}$ \\
\hline 1 (Low) & $\$ 240,832$ & NA & $\$ 366,064$ & $>\$ 366,064$ \\
\hline 1 (High) & $\$ 2,889,984$ & NA & $\$ 4,392,775$ & $>\$ 4,392,775$ \\
\hline 2 & $\$ 5,886,816$ & NA & $\$ 8,947,960$ & $>\$ 8,947,960$ \\
\hline 3 (High) & $\$ 767,000,000$ & $\$ 800,000,000$ & NA & $>\$ 800,000,000$ \\
\hline
\end{tabular}
value of Apache, could greatly decrease the error in $P$ [58]. Before then, the work of environmental economists

Table 1. Summary of values by the different methods for Case Study 1. 
Table 2. Advantages and disadvantages of the methods to determine FOSH design value.

\begin{tabular}{|c|c|c|}
\hline Method & Advantages & Disadvantages \\
\hline$V_{D}$ & Easy to quantify as inputs known & Only at specific time, small error in $P$ \\
\hline$V_{\mathrm{DT}}$ & $\begin{array}{l}\text { Solid input for some products, } \\
\text { future extrapolation has low error }\end{array}$ & Demands future extrapolation and resultant errors for all inputs \\
\hline$V_{\mathrm{DT}}^{\prime}$ & Provides total value with low error & Demands future extrapolation, difficult quantification of secondary benefits \\
\hline$V_{R}$ & Easy calculated precise value for single company & Only useful for single company \\
\hline$V_{r t}$ & $\begin{array}{l}\mathrm{N}_{\mathrm{D}} \text { available and generalized } \\
\text { cost assumptions tolerable }\end{array}$ & $\begin{array}{l}\text { Uses } P \text { and associated errors, assumes all firms have } \\
\text { similar costs and values, demands future extrapolation }\end{array}$ \\
\hline$V_{\mathrm{RT}}$ & Captures value throughout time & $P$ errors, Firm value/costs errors, demands future extrapolation \\
\hline$V_{\mathrm{RT}}^{\prime}$ & $\begin{array}{l}\text { Captures total value with } \\
\text { solid foundation for direct costs }\end{array}$ & $\begin{array}{l}P \text { errors, Firm value/costs errors, Demands future extrapolation, } \\
\text { quantification of secondary benefits difficult }\end{array}$ \\
\hline$V_{M}$ & Easy to calculate & $\begin{array}{l}\text { Only true if mass-scale distributed manufacturing } \\
\text { established at single time, misses all secondary benefits }\end{array}$ \\
\hline$V_{\mathrm{MT}}$ & Relatively easy to calculate & $\begin{array}{l}\text { Only valid if mass-scale distributed manufacturing established, } \\
\text { demands future extrapolation and resultant errors }\end{array}$ \\
\hline$V_{\mathrm{MT}}^{\prime}$ & $\begin{array}{l}\text { Approaching the optimal } \\
\text { deployment and thus value of OSH }\end{array}$ & $\begin{array}{l}\text { Only valid if mass-scale distributed manufacturing established, demands } \\
\text { future extrapolation, estimation of secondary benefits and resultant errors }\end{array}$ \\
\hline
\end{tabular}

using conjoint analysis from marketers, in order to try to estimate consumer values for products that do not currently exist [59] [60] is necessary. Virtually all of this work is based on exhaustive, tedious, expensive and timeconsuming survey research. For the purposes of calculating the return on investment (ROI) in FOSH design the methods here are adequate to provide an economic value for most decision makers. It should be pointed out here, particularly for entities that are trying to leverage their investments for the greatest common good that FOSH development has extremely high potential ROIs as seen by comparing the values in Table 2 and the development costs outlined in Method 2. This provides two or three orders of magnitude in the return. Whereas traditional investments in proprietary development would not come close to such a return, nor would the source be available for others to immediately begin working on rather that the 20-year external innovation hiatus necessary with the current patent system [61].

By publishing open source hardware design that can be manufactured digitally, all development costs are eliminated and barriers to production greatly decreased for everyone throughout the world. As the designs are reusable, with solid modeling and 3-D printing, designs can be expanded or joined together rapidly increasing the rate of innovation following similar observations of FOSS [16]-[18]. The results of the case study confirm these enormous potential values and agree with the sentiment of Nobel laureate Sir John Sulston that research that is open to everyone is at least nine times more valuable to society than research that is closed [62]. The Internet is an example of what happens when channels of communication are left open for participation and growth and FOSS work [63] has demonstrated not only how well the Internet can be used for collaborative developments such as FOSH, but also the efficiency, profitability and opportunities of the open source paradigm over its proprietary counterparts.

\section{Conclusion}

This paper successfully provided three methods of quantifying the value of free and open source hardware in order to provide economic justification for the support in FOSH development investment. The methods are relatively straight-forward to institute and are based on reliable freely-available data with minimal assumptions. The case study presented found millions of dollars of economic value from a relatively simple scientific device being released under open-licenses. This represents orders of magnitude increase in value from proprietary development. It is clear that FOSH development should be funded by organizations interested in maximizing return on public investments particularly in technologies associated with science, medicine and education.

\section{Acknowledgements}

I would like to acknowledge helpful comments from M. Maier, A. Katz, F. Nahrada, E. Velis, W. Breffle, D. 
Kelly, C. Adamez, G. Niezen, H. Kyriakou, J. Serrano, D. Kelly, W. Tebbens and D. Denkenberger.

\section{References}

[1] Economist (2012) A Third Industrial Revolution: Manufacturing and Innovation. The Economist.

[2] Corney, J. (2005) The Next and Last Industrial Revolution? Assembly Automation, 25, 257. http://dx.doi.org/10.1108/aa.2005.03325daa.002

[3] Gershenfeld, N. (2005) Fab. Basic Books, New York.

[4] Lipson, H. and Kurman, M. (2013) Fabricated. John Wiley \& Sons, New York.

[5] Pearce, J.M. (2012) Building Research Equipment with Free, Open-Source Hardware. Science, 337, $1303-1304$. http://dx.doi.org/10.1126/science.1228183

[6] Jones, N. (2012) Science in Three Dimensions: The Print Revolution. Nature, 487, 22-23. http://dx.doi.org/10.1038/487022a

[7] Kühnle, H. (2010) Distributed Manufacturing. Springer, Berlin. http://dx.doi.org/10.1007/978-1-84882-707-3

[8] Pearce, J.M., Blair, C., Laciak, K., Andrews, R., Nosrat, A. and Zelenika-Zovko, I. (2010) 3-D Printing of Open Source Appropriate Technologies for Self-Directed Sustainable Development. Journal of Sustainable Development, 3, $17-29$.

[9] Khademhosseini, A., Langer, R., Borenstein, J. and Vacanti, J.P. (2006) Microscale Technologies for Tissue Engineering and Biology. Proceedings of the National Academy of Sciences of the United States of America, 103, 2480-2487. http://dx.doi.org/10.1073/pnas.0507681102

[10] Derby, B. (2012) Printing and Prototyping of Tissues and Scaffolds. Science, 338, 921-926.

http://dx.doi.org/10.1126/science.1226340

[11] Schaedler, T.A., Jacobsen, A.J. and Carter, W.B. (2013) Toward Lighter, Stiffer Materials. Science, 341, 1181-1182. http://dx.doi.org/10.1126/science.1243996

[12] Connell, J.L., Ritschdorff, E.T., Whiteley, M. and Shear, J.B. (2013) 3D Printing of Microscopic Bacterial Communities. Proceedings of the National Academy of Sciences of the United States of America, 110, 18380-18385. http://dx.doi.org/10.1073/pnas.1309729110

[13] Wittbrodt, B., Glover, A., Laureto, J., Anzalone, G., Oppliger, D., Irwin, J. and Pearce, J.M. (2013) Life-Cycle Economic Analysis of Distributed Manufacturing with Open-Source 3-D Printers. Mechatronics, 23, 713-726. http://dx.doi.org/10.1016/j.mechatronics.2013.06.002

[14] Sells, E., Smith, Z., Bailard, S., Bowyer, A. and Olliver, V. (2010) RepRap: The Replicating Rapid Prototype: Maximizing Customizability by Breeding the Means of Production. In: Piller, F.T. and Tseng, M.M., Eds., Handbook of Research in Mass Customization and Personalization, World Scientific Publishing Company, Singapore City, 1-34.

[15] Jones, R., Haufe, P. and Sells, E. (2011) RepRap—The Replicating Rapid Prototype. Robotica, 29, 177-191. http://dx.doi.org/10.1017/S026357471000069X

[16] Lakhani, K.R. and Hippel, E.V. (2003) How Open Source Software Works: "Free” User to User Assistance. Research Policy, 32, 923-943. http://dx.doi.org/10.1016/S0048-7333(02)00095-1

[17] Ball, P. (2003) Openness Makes Software Better Sooner. Nature. http://dx.doi.org/10.1038/news030623-6

[18] Deek, F.P. and McHugh, J.A.M. (2008) Open Source: Technology and Policy. Cambridge University Press, New York.

[19] Wohlers, T. and Caffrey, T. (2014) Wohlers Report 2014: 3D Printing and Additive Manufacturing State of the Industry Annual Worldwide Progress Report. Wohlers Associates.

[20] Zhang, C., Anzalone, N.C., Faria, R.P. and Pearce, J.M. (2013) Open-Source 3D-Printable Optics Equipment. PLoS ONE, 8, e59840. http://dx.doi.org/10.1371/journal.pone.0059840

[21] Pearce, J.M. (2014) Open-Source Lab: How to Build Your Own Hardware and Reduce Research Costs. Elsevier, New York.

[22] Mahajan, V. and Peterson, R.A. (1985) Models for Innovation Diffusion. Sage, Thousand Oaks.

[23] Jensen, R. (1982) Adoption and Diffusion of an Innovation of Uncertain Profitability. Journal of Economic Theory, 27, 182-193. http://dx.doi.org/10.1016/0022-0531(82)90021-7

[24] Gopalakrishnan, S. and Damanpour, F. (1997) A Review of Innovation Research in Economics, Sociology and Technology Management. Omega, 25, 15-28. http://dx.doi.org/10.1016/S0305-0483(96)00043-6

[25] Meade, N. and Islam, T. (2006) Modelling and Forecasting the Diffusion of Innovation-A 25-Year Review. International Journal of Forecasting, 22, 519-545. http://dx.doi.org/10.1016/j.ijforecast.2006.01.005 
[26] Wijnen, B., Hunt, E.J., Anzalone, G.C. and Pearce, J.M. (2014) Open-Source Syringe Pump Library. PLoS ONE, 9, e107216. http://dx.doi.org/10.1371/journal.pone.0107216

[27] http://openscad.org

[28] http://reprap.org/

[29] http://www.appropedia.org/Open-source syringe pump

[30] http://www.raspberrypi.org/

[31] http://www.thingiverse.com/thing:475841

[32] https://www.youmagine.com/designs/syringe-pump

[33] http://www.glassdoor.com/Salaries/cad-engineer-salary-SRCH_KO0,12.htm

[34] http://www.glassdoor.com/Salaries/software-engineer-salary-SRCH KO0,17.htm

[35] http://fab.cba.mit.edu/classes/4.140/people/wildebeest/projects/final/index.html

[36] http://hackaday.io/project/1838-Open-Syringe-Pump

[37] http://www.openpump.org/index.html

[38] Tranparency Market Research (2014) Infusion Pumps Market (Large Volume, Disposable, Syringe, Ambulatory, Implantable)—Global Industry Analysis, Size, Share, Growth, Trends and Forecast, 2013-2019.

[39] Parkin, M., Powell, M. and Matthews, K. (2002) Economics. Addison-Wesley, Harlow.

[40] Frank, R. (2008) Microeconomics and Behavior. McGraw-Hill, New York.

[41] Png, I. (1999) Managerial Economics. Blackwell, Hoboken.

[42] Jan, T. (2013) Harvard, MIT Thwart Effort to Cap Overhead Payments. Boston Globe, 3-17-2013.

[43] Pearce, J.M. (2014) It Is Time to Move Research Expenditures to the Denominator in University Metrics. Academe, 100. http://www.aaup.org/article/it-time-move-research-expenditures-denominator-university-metrics

[44] Dolan, P., Shaw, R., Tsuchiya, A. and Williams, A. (2005) QALY Maximisation and People’s Preferences: A Methodological Review of the Literature. Health Economics, 14, 197-208. http://dx.doi.org/10.1002/hec.924

[45] Rice, D.P. and Cooper, B.S. (1967) The Economic Value of Human Life. American Journal of Public Health and the Nations Health, 57, 1954-1966. http://dx.doi.org/10.2105/AJPH.57.11.1954

[46] Linnerooth, J. (1979) The Value of Human Life: A Review of the Models. Econ Inquiry, 17, 52-74. http://dx.doi.org/10.1111/j.1465-7295.1979.tb00295.x

[47] Dorman, P. (2009) Markets and Mortality. Cambridge University Press, Cambridge.

[48] Evans, J.R., Hall, K.L. and Warford, J. (1981) Health Care in the Developing World: Problems of Scarcity and Choice. Population, 61, 74.

[49] UN High Commissioner for Human Rights, WHO. The Right to Health. Fact Sheet 31.

[50] Kreiger, M. and Pearce, J.M. (2013) Environmental Life Cycle Analysis of Distributed 3-D Printing and Conventional Manufacturing of Polymer Products. ACS Sustainable Chemistry \& Engineering, 1, 1511-1519. http://dx.doi.org/10.1021/sc400093k

[51] Baechler, C., De Vuono, M. and Pearce, J.M. (2013) Distributed Recycling of Waste Polymer into RepRap Feedstock. Rapid Prototyping Journal, 19, 118-125. http://dx.doi.org/10.1108/13552541311302978

[52] King, D.L., Babasola, A., Rozario, J. and Pearce, J.M. (2014) Mobile Open-Source Solar-Powered 3-D Printers for Distributed Manufacturing in Off-Grid Communities. Challenges in Sustainability, 2, 18-27. http://dx.doi.org/10.12924/cis2014.02010018

[53] Bovea, M.D. and Vidal, R. (2004) Increasing Product Value by Integrating Environmental Impact, Costs and Customer Valuation. Resources, Conservation and Recycling, 41, 133-145. http://dx.doi.org/10.1016/j.resconrec.2003.09.004

[54] McPherson, A., Proffitt, B. and Hale-Evans, R. (2008) Estimating the Total Development Cost of a Linux Distribution. Linux Foundation.

[55] Google (2013) Mapping Creates Jobs and Drives Global Economic Growth. Google.

[56] Divis, D.A. (2013) Difficult Task: Placing an Economic Value on GPS. http://www.insidegnss.com/node/3833

[57] http://www.valueoftheweb.com/

[58] Greenstein, S. and Nagle, F. (2014) Digital Dark Matter and the Economic Contribution of Apache. Research Policy, 43, 623-631. http://dx.doi.org/10.1016/j.respol.2014.01.003

[59] Alriksson, S. and Öberg, T. (2008) Conjoint Analysis for Environmental Evaluation. Environmental Science and Pollution Research, 15, 244-257. http://dx.doi.org/10.1065/espr2008.02.479 
[60] Green, P.E. and Srinivasan, V. (1990) Conjoint Analysis in Marketing: New Developments with Implications for Research and Practice. Journal of Marketing, 54, 3-19. http://dx.doi.org/10.2307/1251756

[61] Boldrin, M. and Levine, D.K. (2008) Against Intellectual Monopoly. Cambridge University Press, Cambridge.

[62] Love, J. (2014) The Value of an Open-Source Dividend. http://www.managingip.com/Blog/3390962/The-value-of-an-open-source-dividend.html

[63] Raymond, E. (1999) The Cathedral and the Bazaar. Knowledge, Technology \& Policy, 12, 23-49. http://dx.doi.org/10.1007/s12130-999-1026-0 
Scientific Research Publishing (SCIRP) is one of the largest Open Access journal publishers. It is currently publishing more than 200 open access, online, peer-reviewed journals covering a wide range of academic disciplines. SCIRP serves the worldwide academic communities and contributes to the progress and application of science with its publication.

Other selected journals from SCIRP are listed as below. Submit your manuscript to us via either submit@scirp.org or Online Submission Portal.
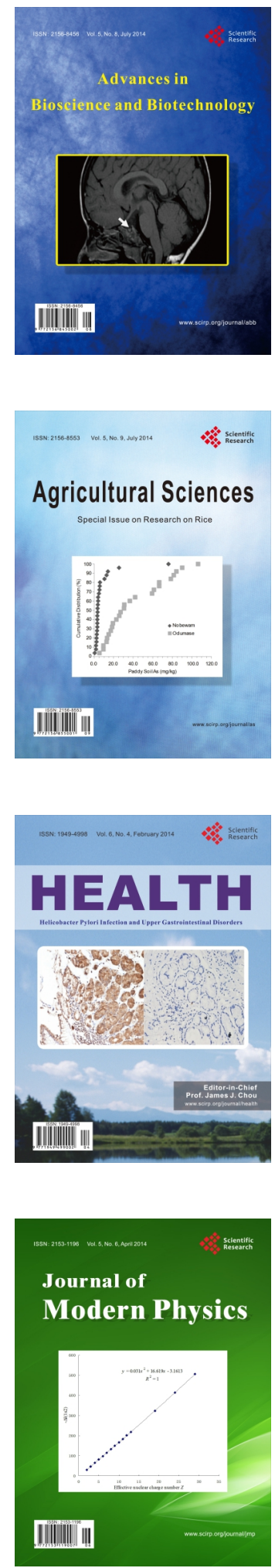
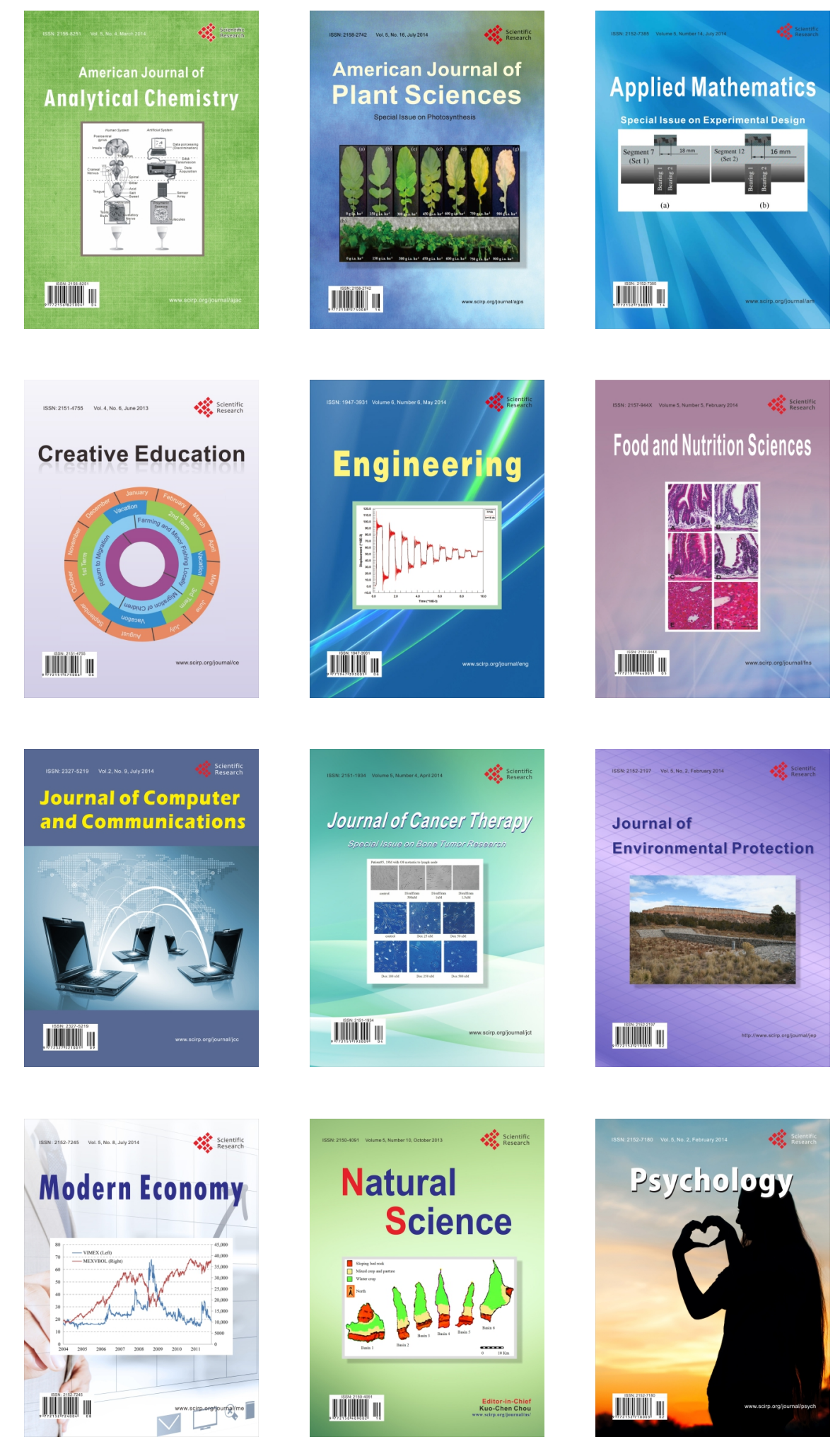